\title{
The Accuracy of Physician View of Endpoint for Elderly Patient in ICU at Admission and Actual Discharge Outcome
}

\author{
Ahmed F Shaheen, Rania M A Elakkad, Manar M A Mamoun, and Ahmed K Mortagy \\ Geriatric Medicine\& Gerontology department, Faculty of Medicine, Ain Shams University, Cairo, Egypt. \\ Correspondence: cairo1981@gmail.com
}

\begin{abstract}
Background: The average age and life expectancy of the population are increasing and so a growing number of elderly patients are being admitted to the intensive care unit

Aim: To detect the accuracy of the physician view of endpoint on ICU admission and actual discharge outcome

Methods: A prospective cohort study conducted on140 elderly patients (60 years and above) admitted to medical ICU with acute illness, each patient was subjected to complete medical history, physical examination and assessment of medical comorbidities, ICU mortality scores: (APACHE II, SAPS II, MPM II 0, MPM24) and calculation of the predicted mortality, establishment of intensivist point of view regarding the predicted outcome and establishment of end point of each patient (either discharge or death).
\end{abstract}

Conclusions: There is a highly significant association between physician view of end point of the patient on ICU admission and actual discharge of the patients in ICU

Keywords: Mortality prediction, Critically ill elderly, ICU discharge

\section{Background}

It is clear that a sizeable proportion of intensive care unit (ICU) patients are older adults. Data from the United States estimates approximately $55 \%$ of all ICU bed-days are occupied by patients aged $\geq 65$ years and an estimated $14 \%$ of those patients aged $\geq 85$ years die in the ICU. ${ }^{1}$

The concept of disease severity is difficult to define; the Subcommittee on Disease Severity concluded that the severity is the total effect of disease on organ function: it has both irreversible and reversible components. $^{2}$

Predicting outcomes for critically ill patients is an important aspect of discussions with families in the intensive care unit. Physician job is to clinically predict the expected outcomes ${ }^{3}$

The Severity of illness scoring systems are tools used to predict and to evaluate, from multiple perspectives, the outcomes of critically ill patients.

To date, multiple tools exist. They differ with respect to the variables they measure, and if they try to describe ICU mortality or hospital mortality. (APACHE) score is commonly used in the United States and the (SAPS) system is more regularly employed in Europe ${ }^{4}$

Sinuff et al., 2005 performed a systematic review of 12 observational studies comparing the accuracy of ICU physicians' clinical judgment and scoring system predictions of ICU or hospital mortality of critically ill adults. They found that ICU physicians discriminate between survivors and non-survivors more accurately than do scoring systems in the first $24 \mathrm{hrs}$ of ICU admission. 5

\section{Methods}

A prospective cohort study was conducted in medical Intensive Care Units. The study has been conducted on 140 elderly patients (60 years and above) admitted to medical ICU with acute illness. Patients admitted to ICU for planned postoperative monitoring or due to trauma or other critical surgical causes were excluded. 
Each patient was subjected to:

1. Complete medical history and assessment of comorbidities and current status on admission

2. Physical examination and recording of vital data on admission ,assessment of consciousness level and recording of the worst parameters during first 24 hours of admission

3. ICU mortality scores on hospital admission:

- APACHE II (The acute physiology and chronic health evaluation II). The original APACHE score was developed in 1981 to quantify severity of illness and was divided into two sections: a physiology score to assess the degree of acute illness; and a pre-admission characters to determine the chronic health status of the patient, more recent editions of APACHE were generated ${ }^{6}$

- SAPS II(Simplified acute physiology score II) it predicts ICU mortality using a combination of 17 variables: 12 physiological variables, age, type of admission, and 3 variables related to underlying disease

- MPM II (Mortality probability model II on admission (MPM II 0) and after 24h of admission MPM II 24h) ${ }^{8}$ It contains 15 variables; and $\mathrm{MPM}_{24}$ which contains 5 of the admission variables and 8 additional variables and is designed for patients who stay in the ICU for more than 24 hours.

4. Establishment of end point of each patient (either discharge or death), physician point of view on hospital admission.

\section{Statistical Analysis}

Analysis of data performed by using SPSS package version 15.0. Description of data in the form of mean (M) and standard deviation (SD) for all quantitative variables and frequency and percentage for all qualitative variables. Comparison of qualitative variables was done using chi-square test (X2). Significance levels measured according to $\mathrm{P}$ value (probability) $\mathrm{P}>0.05$ insignificant, $\mathrm{P}<0.05$ significant, $\mathrm{P}<0.01$ highly significant.

\section{Results}

The results showed that age group ranged from 60 years to 96 years and the actual discharge from the ICU was $40.71 \%$ of patients while $59.29 \%$ of patients died, it also showed that the length of ICU stay ranged from 2 days to 62 days (table 1) .

The results showed that table shows a highly significant association between physician view of end point of the patient on ICU admission and actual discharge of the patient (table 2)

The physician view of end point matched the actual discharge in 102 patients $(51$ death cases and 51 discharge cases) out of 140 patients

The result showed a highly significant relationship between the predictive value of the mortality scales (APACHE II, SAPS II, MPM II admission and MPM II at 24 hours) either death or discharge and the actual discharge type (table 3 ) .

The result showed that physician view of endpoint has a highly significant association with the predictive value of SAPS II, MPM II admission, MPM II at $24 \mathrm{~h}$ and a significant association with APACHE II scoring system (table 4).

Table 1: Demography of the study population

\begin{tabular}{|c|c|c|c|}
\hline & & N. & $\begin{array}{l}\text { Percent } \\
(\%)\end{array}$ \\
\hline \multirow[t]{2}{*}{ Sex } & Male & 66 & 47.14 \\
\hline & Female & 74 & 52.86 \\
\hline \multirow[t]{3}{*}{ Age } & Mean \pm SD & \multicolumn{2}{|l|}{$70.0 \pm 8.14$} \\
\hline & Min. & \multicolumn{2}{|l|}{60} \\
\hline & Max. & \multicolumn{2}{|l|}{96} \\
\hline \multirow{2}{*}{$\begin{array}{l}\text { Actual } \\
\text { discharge } \\
\text { type }\end{array}$} & Death & 83 & 59.29 \\
\hline & Discharge & 57 & 40.71 \\
\hline \multirow{3}{*}{$\begin{array}{l}\text { Length of } \\
\text { ICU stay }\end{array}$} & Mean \pm SD & $9.8 \pm 9.2$ & \\
\hline & Min. & \multicolumn{2}{|l|}{2} \\
\hline & Max. & \multicolumn{2}{|l|}{62} \\
\hline
\end{tabular}

Table (2): Relationship between physician view of endpoint and actual discharge type in studied group

\begin{tabular}{|c|c|c|c|c|}
\hline \multirow{2}{*}{\multicolumn{2}{|c|}{ Actual outcome }} & \multicolumn{2}{|c|}{$\begin{array}{l}\text { Physician view of end } \\
\text { point }\end{array}$} & \multirow[t]{2}{*}{$\mathrm{P}$ value } \\
\hline & & Death & Discharge & \\
\hline \multirow[t]{2}{*}{ death } & $\mathrm{N}$ & 51 & 32 & \multirow[t]{4}{*}{0.000} \\
\hline & $\%$ & 89.47 & 38.55 & \\
\hline \multirow[t]{2}{*}{ Discharge } & $\mathrm{N}$ & 6 & 51 & \\
\hline & $\%$ & 10.52 & 61.44 & \\
\hline
\end{tabular}

Table (3): Relationship between the predictive value of the mortality scales and the actual discharge type.

\begin{tabular}{|c|c|c|c|}
\hline & \multicolumn{2}{|l|}{ discharge type } & \\
\hline & death & discharge & \\
\hline & Mean $\pm \mathrm{SD}$ & Mean \pm SD & $\mathrm{P}$-value \\
\hline APACHE II & $47.41 \pm 22.27$ & $34.17 \pm 17.94$ & $<0.001^{*}$ \\
\hline SAPS II & $51.46 \pm 26.80$ & $25.29 \pm 18.39$ & $<0.001 *$ \\
\hline MPM. II AD & $57.18 \pm 25.27$ & $30.17 \pm 17.8$ & $<0.001 *$ \\
\hline MPM II 24 & $52.12 \pm 27.18$ & $28.40 \pm 19.96$ & $<0.001 *$ \\
\hline
\end{tabular}


Table (4): Relationship between different scoring systems in relation to physician view of endpoint among studied group

\begin{tabular}{|c|c|c|c|c|}
\hline & $\begin{array}{l}\text { Physician view } \\
\text { of end point }\end{array}$ & $\mathrm{N}$ & $\begin{array}{l}\text { Mean } \\
\pm \text { SD }\end{array}$ & $\mathrm{p}$ \\
\hline \multirow[t]{2}{*}{ APACHE II } & Death & 57 & $\begin{array}{l}63.57 \\
\pm 22.78\end{array}$ & \multirow[t]{2}{*}{0.01} \\
\hline & Discharge & 83 & $\begin{array}{l}34.68 \\
\pm 16.58\end{array}$ & \\
\hline \multirow[t]{2}{*}{ SAPS II } & Death & 57 & $\begin{array}{l}59.18 \\
\pm 26.38\end{array}$ & \multirow[t]{2}{*}{0.00} \\
\hline & Discharge & 83 & $\begin{array}{l}28.20 \\
\pm 19.00\end{array}$ & \\
\hline \multirow[t]{2}{*}{ MPM. II ad } & Death & 57 & $\begin{array}{l}61.08 \\
\pm 24.27\end{array}$ & \multirow[t]{2}{*}{0.00} \\
\hline & Discharge & 83 & $\begin{array}{l}36.04 \\
\pm 22.27\end{array}$ & \\
\hline \multirow[t]{3}{*}{ MPM II 24h } & Death & 57 & $\begin{array}{l}57.76 \\
\pm 26.53\end{array}$ & \multirow[t]{3}{*}{0.00} \\
\hline & Discharge & 83 & $\begin{array}{l}31.97 \\
\pm 22.11\end{array}$ & \\
\hline & Discharge & 10 & $\begin{array}{l}10.80 \\
\pm 3.16\end{array}$ & \\
\hline
\end{tabular}

\section{Discussion}

The results of this study revealed a highly significant association between physician view of end point of the patient on ICU admission and actual discharge of the patient.

This agrees with Sinuff et al ., ${ }^{5}$ who performed a systematic review of 12 observational studies comparing the accuracy of ICU physicians' and scoring system predictions of ICU or hospital mortality of critically ill adults and concluded that : ICU physicians discriminated between survivors and non-survivors more accurately than did scoring systems in the first 24 hrs of ICU admission but neither physicians nor scoring systems were accurate enough to rely on during triage and end-of-life decisions ${ }^{5}$

On the other hand some evidence suggests that statistical methods behave better than clinicians in predicting outcome in many studies. ${ }^{9}$ This opinion is, however, controversial especially for decisions to withdraw or to withhold therapy. Moreover, the application of different models to the same patient frequently results in very different predictions ${ }^{9}$, but most of studies were not specifically on the elderly patient.

In the current study the result showed that physician view of endpoint has a highly significant positive association with the predictive value of the well validated mortality prediction tools SAPS II, MPM II admission, MPM II at $24 \mathrm{~h}$ and a significant association with APACHE II scoring system and this adds a value for the clinical judgment.
This agrees with many studies as Chang et al., ${ }^{10}$ Knaus et al. ${ }^{11}$ and Zimmerman et $\mathrm{al}^{12}$ which concluded that mortality scales is a helping tool to the decision making process and not a substitute.

Moreover, outcome prediction may be affected by the inappropriate interpretation of the score. Clinicians must be aware that the probability of mortality based on a particular score relates to a similar group of patients and not to an individual. This is important to understand before attempting to use scoring systems in clinical practice. ${ }^{13}$

Another opinion was that the superiority of physician judgment to objective scores could be attributed to physicians giving less appropriate treatment approach to patients they predicted to die, thus worsening their prognosis. ${ }^{14}$

Scholz et al., 2004 reported that physicians' prognosis was not based only on objective scoring systems, but actually more based on experience and individual observations. ${ }^{15}$

Scoring systems can be used to assist the clinical judgment; being objective measures of patients 'disease severity, can therefore reflect the likelihood of mortality in a homogenous cohort of patients. ${ }^{16}$

\section{References}

1. Angus DC, Barnato AE, Linde-Zwirble WT, Weissfeld LA, Watson RS, Rickert T, Rubenfeld GD 2004: Use of intensive care at the end of life in the United States: an epidemiologic study. Crit Care Med. $2004 \mathrm{Mar} ; 32(3): 638-43$.

2. Medsger TA Jr, Bombardieri S, Czirjak L, Scorza R, Della Rossa A, Bencivelli W: Assessment of disease severity and prognosis. Clin Exp Rheumatol. 2003;21(3 Suppl 29):S42-6.

3. Rocker G, Cook D, Sjokvist P, Weaver B, Finfer S, McDonald E, Marshall J, Kirby A, Levy M, Dodek P, Heyland D, Guyatt G : Clinician predictions of intensive care unit mortality, Crit Care Med. 2004 May;32(5):1149-54.

4. Shorr AF ,Zilberberg MD, Luippold RS, Sulsky S 2008: Prolonged acute mechanical ventilation, hospital resource utilization, and mortality in the United States. Crit Care Med. 2008 Mar;36(3):72430 .

5. Sinuff Tasnim, Adhikari Neill K. J,Cook Deborah JSchünemann Holger J,Somme D, Maillet JM, Gisselbrecht M, et al. 2003:Critically ill old and the oldest-old patients in intensive care: short- and longterm outcomes. Intensive Care Med. 2003;29:2137-2143

6. Knaus WA, Draper EA, Wagner DP, Zimmerman JE 1985:.. APACHE II : A severity of disease classification system. Crit Care Med. 1985;13:818-29.

7. Le Gall JR, Lemeshow S, Saulnier F. A new Simplified Acute Physiology Score (SAPS II) based on a European/North American multicenter study. JAMA 1993; 270:2957.

8. Lemeshow S, Le Gall JR. Modeling the severity of illness of ICU patients. A systems update. JAMA 1994; 272: 272: 1049-55

9. Moreno Rui P. and Metnitz Philipp G.H.2008:Severity Scoring Systems: Tools for the Evaluation of Patients and Intensive Care Units. Elsevier Inc Parrillo\& Dellinger: Critical Care Medicine, 3rd ed. 
Shaheen et al. EJGG.2015; 2(2):22-25

10. Chang RWS, Lee B, Jacobs S, Lee B: Accuracy of decisions to withdraw therapy in critically ill patients: Clinical judgement versus a computer model. Crit Care Med 1989; 17:1091-1097.

11. Knaus WA, Rauss A, Alperovitch A, et al: Do objective estimates of chances for survival influence decisions to withhold or withdraw treatment?. Med Decis Making 1990; 10:163-171.

12. Zimmerman JE, Wagner DP, Draper EA, Knaus WA: Improving intensive care unit discharge decisions: Supplementary physician judgment with predictions of next day risk for life support. Crit Care Med 1994; 22:1373-1384

13. D. Christopher Bouch and Jonathan P. Thompson. Severity scoring systems in the critically ill. Contin Educ Anaesth Crit Care Pain. 2008. 8 (5): 181-185

14. MCCLISH DK, POWELL SH, How Well Can Physicians Estimate Mortality in a Medical Intensive Care Unit? (Med Decis Making 1989;9:125-132)

15. Scholz, N., Bäsler, K., Saur, P., Burchardi, H. and Felder, S. (2004) 'Outcome prediction in critical care: physicians' prognoses vs. scoring systems', European Journal of Anaesthesiology, 21(8), pp. 606-611. doi: 10.1017/S026502150400804X.

16. Lemeshow S, Le Gall JR. Modelling the severity of illness of ICU patients: a systems update. J Am Med Assoc 1994;272:1049-55. 